\title{
Minimally invasive combined approach for an hourglass-shaped mass at the thoracic inlet
}

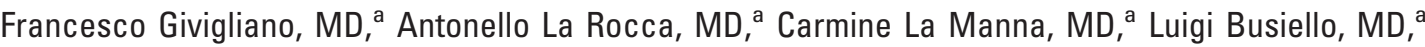 \\ Francesco Longo, MD, ${ }^{\mathrm{b}}$ Francesco Scognamiglio, MD, ${ }^{a}$ Francesco Ionna, MD, ${ }^{\mathrm{b}}$ and \\ Gaetano Rocco, MD, FRCS (Ed), FECTS, ${ }^{a}$ Naples, Italy
}

Supplemental material is available online.

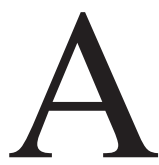
variety of surgical approaches have been proposed for malignant tumors located at the thoracic inlet. Usually, local invasiveness either precludes surgery or imposes wide exposure for extended resections. The attendant morbidity may not be justified when dealing with benign lesions, which should be removed in accordance with a conservative surgical strategy.

\section{Clinical Summary}

A 48-year-old man was referred for diagnosis of a bulging mass in the left supraclavicular fossa detected suddenly after moderate weight lifting. On examination, the lesion seemed cystic and was

From the Divisions of Thoracic Surgery ${ }^{\mathrm{a}}$ and Head and Neck Surgery, National Cancer Institute, Pascale Foundation, Naples, Italy.

Received for publication Jan 19, 2007; accepted for publication March 8, 2007.

Address for reprints: G. Rocco, MD, FRCS (Ed), FECTS, Chief, Thoracic Surgery, National Cancer Institute, Pascale Foundation, Via Semmola 81, 80131, Naples, Italy (E-mail: Gaetano.Rocco@btopenworld.com).

J Thorac Cardiovasc Surg 2007;134:528-9

$0022-5223 / \$ 32.00$

Copyright (C) 2007 by The American Association for Thoracic Surgery doi:10.1016/j.jtcvs.2007.03.019 neither painful nor mobile. A chest computed tomographic scan and subsequent magnetic resonance imaging showed a $3 \times 7 \mathrm{~cm}$ hourglass mass protruding from the left supraclavicular area into the apex of the hemithorax (Figure 1). Despite a negative preoperative workup for malignancy (including a positron emission tomographic scan study), the patient insisted on having this lesion removed. We decided to approach the lesion in a minimally invasive fashion from the neck and from the chest. Two surgical teams simultaneously performed a short left supraclavicular cervicotomy and uniportal video-assisted thoracic surgery (VATS) through which the lesion was isolated from the neurovascular structures of the thoracic inlet and removed (Figure 2). The postoperative course was uneventful, and the patient was discharged on postoperative day 2 (Figure E1). Final pathologic examination demonstrated a lipoma with benign histologic features.

\section{Discussion}

In the literature, lipomas originating from the fat tissue of the pleural apex have been previously described. ${ }^{1}$ In addition, many different types of lesions have been identified in the supraclavicular fossa with the potential of insinuating into the chest, thereby requiring combined surgical attention for diagnosis and treatment. ${ }^{2}$

Intrathoracic lipomas can be successfully resected by traditional VATS ${ }^{3}$ but in most cases these lesions are well defined in their anatomic position, thus making the resection achievable through one thoracic approach. Recently, single-port (uniportal) VATS has been successfully used in the diagnosis and treatment of several intrathoracic conditions, resulting in decreased postoperative pain and paresthesia. ${ }^{4}$

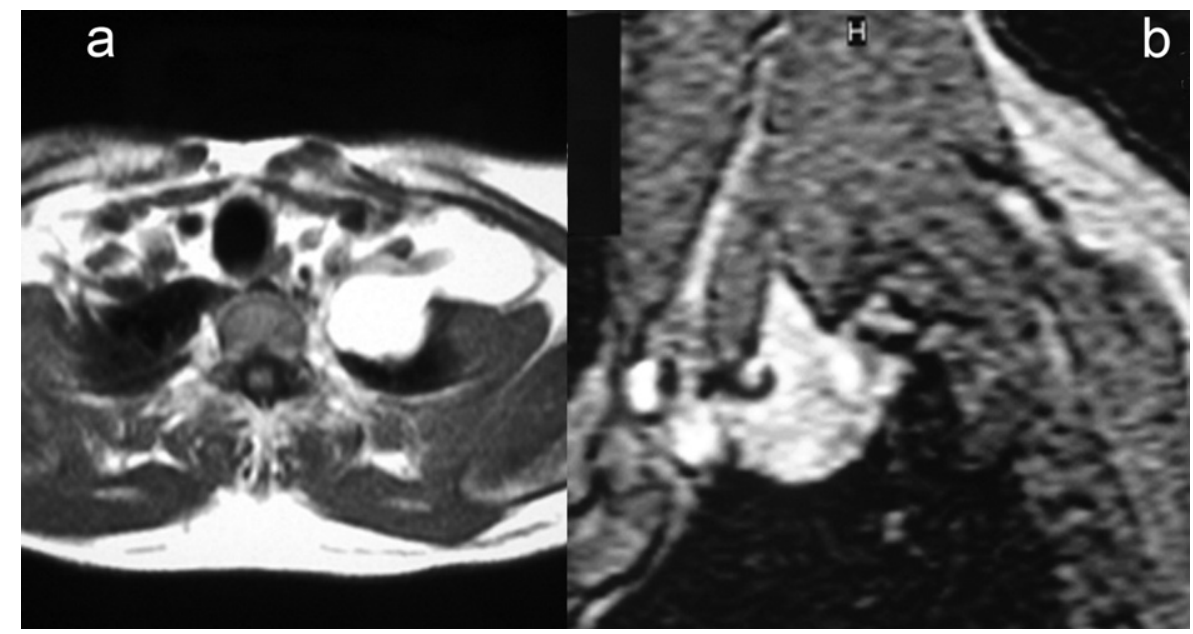

Figure 1. Magnetic resonance image demonstrating the "hourglass-shaped mass at the thoracic inlet. a, Axial view; b, sagittal view. 


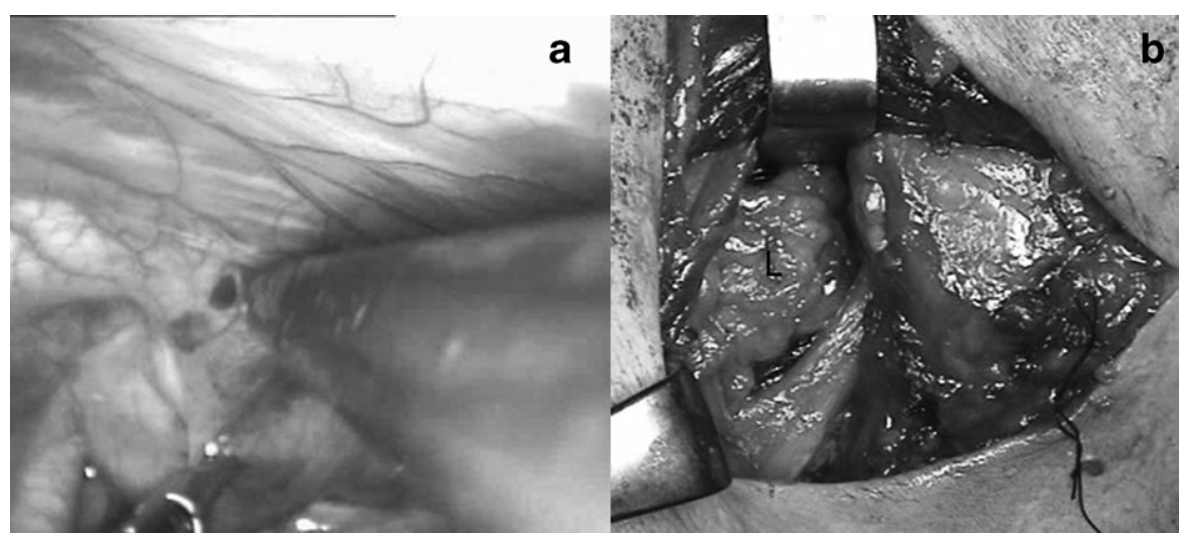

Figure 2. Intraoperative views: a, Uniportal VATS identification and dissection of the pleural mass; $b$, neck dissection of the cervicothoracic lipoma (L).

In our case, the combined cervical and uniportal VATS approach was justified by the uncertainty of the diagnosis, given the numerous differentials suggested by the radiologist. Among them, given the recent history, the possibility of a lesion originating from the thoracic duct was considered, thus necessitating intrathoracic visualization of the lesion. ${ }^{5}$

We anticipate that uniportal VATS could be used in other situations when optimal control of a mass in the thoracic inlet is necessary. In addition, transillumination from the chest may facilitate the dissection in the supraclavicular area. In this setting, during combined cervicothoracic procedures, the uniportal VATS approach can be used with a morbidity comparable with that of a simple chest drain incision and with the same advantage, described with traditional VATS, of rendering the identification of the anatomic structures at the thoracic inlet more reliable and the dissection more secure.

\section{References}

1. Dissmann E. Intrathoracic lipoma of the pleural cupula. Fortschr Geb Rontgenstr Nuklearmed. 1950;73:102-4.

2. Yamaguchi M, Yoshino I, Kameyama T, Osoegawa A, Tagawa T, Maehara Y. Thoracoscopic surgery combined with a supraclavicular approach for removing a cervico-mediastinal neurogenic tumor: a case report. Ann Thorac Cardiovasc Surg. 2006;12:194-6.

3. Naruse H, Katayama Y, Inada K, Ikeda T. An adult case of intrathoracic chest wall type lipoma by VATS resection. Kyobu Geka. 1998;51:517-20.

4. Jutley RS, Khalil MW, Rocco G. Uniportal vs standard three-port VATS technique for spontaneous pneumothorax: comparison of postoperative pain and residual paraesthesia. Eur J Cardiothorac Surg. 2005;28:43-6.

5. Ray J, Braithwaite D, Patel PJ. Spontaneous thoracic duct cyst. Eur Arch Otorhinolaryngol. 2003;260:280-2. 


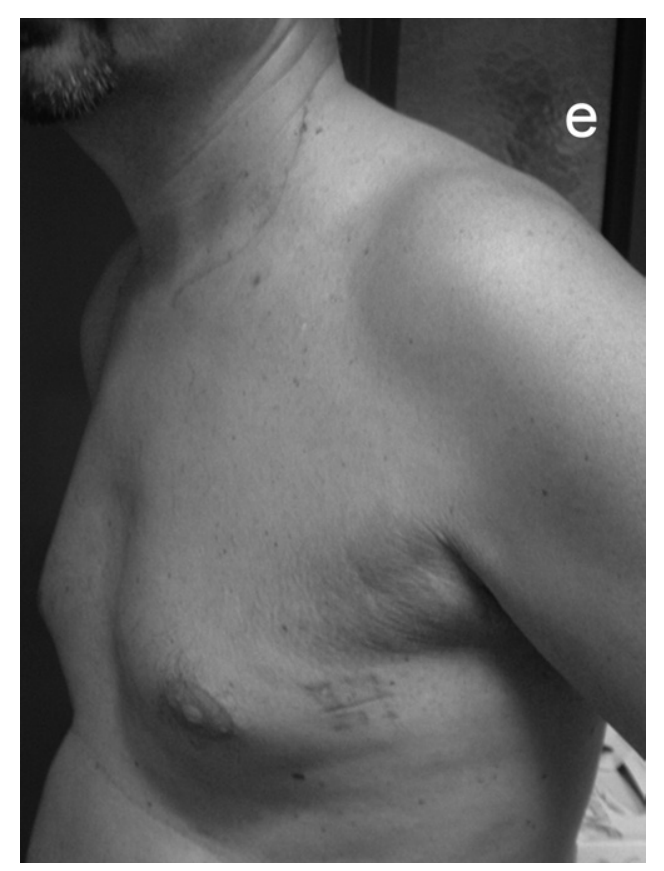

Figure E1. The patient at the 2-week follow-up visit. 